\title{
Outcome of patients admitted to the intensive care unit for acute exacerbation of idiopathic pulmonary fibrosis
}

\author{
Fahad M Al-Hameed MD FRCPC, Sat Sharma MD FRCPC FCCP
}

FM Al-Hameed, S Sharma. Outcome of patients admitted to the intensive care unit for acute exacerbation of idiopathic pulmonary fibrosis. Can Respir J 2004;11(2):117-122.

RATIONALE: The aim of this study was to evaluate the outcome of intensive care unit (ICU) admission in patients with idiopathic pulmonary fibrosis (IPF) who develop acute respiratory failure of unknown etiology. METHODS: A retrospective study at University of Manitoba hospitals reviewed all patients admitted to the ICU from November 1988 to December 2000 with IPF requiring mechanical ventilation for unknown causes of acute respiratory failure. Survival at hospital discharge was assessed as the primary end point and ICU length of stay as a secondary end point. In the absence of open lung biopsy, major and minor clinical criteria (as per American Thoracic Society statements) were used for the diagnosis of IPF. Infections were ruled out by extensive surveillance cultures and/or bronchoscopy with bronchoalveolar lavage.

RESULTS: Eighty-eight charts were reviewed and 25 patients met the inclusion criteria. The mean $( \pm$ SD) age was $69 \pm 11$ years (range 42 to 96 years) and 23 patients were male. With the exception of one survivor who was discharged home, 21 patients died while receiving mechanical ventilation, and three patients died in hospital shortly after ICU discharge (one day, 22 days and 67 days). Intubation and mechanical ventilation were administered to 21 patients, with a mean duration of $11 \pm 6$ days (range two to 27 days); the other four patients were treated with noninvasive ventilation. The average duration of symptoms before ICU admission was $22 \pm 26$ days. All patients were treated with systemic corticosteroids, while eight patients received additional chemotherapy. CONCLUSIONS: In the absence of a reversible cause, patients with IPF who develop acute exacerbation of IPF may not benefit from ICU admission and mechanical ventilation. However, it is imperative that a diagnostic workup be performed to rule out an infectious or other reversible cause of respiratory failure before admission to the ICU is denied.

Key Words: Acute respiratory failure; Idiopathic pulmonary fibrosis; Intensive care unit; Interstitial lung disease; Mechanical ventilation
L'issue de patients admis à l'unité de soins intensifs par suite d'une exacerbation aiguë de la fibrose pulmonaire idiopathique

JUSTIFICATION : La présente étude visait à évaluer l'issue de l'hospitalisation à l'unité de soins intensifs (USI) de patients atteints de fibrose pulmonaire idiopathique (FPI) qui développent une insuffisance respiratoire aiguë d'étiologie inconnue.

MÉTHODOLOGIE : Une étude rétrospective menée dans les hôpitaux de l'université du Manitoba a permis d'examiner tous les patients admis à l'USI entre novembre 1998 et décembre 2000 en raison d'une FPI exigeant une ventilation mécanique découlant de causes inconnues d'insuffisance respiratoire aiguë. La survie au congé était évaluée comme le résultat primaire, et la durée du séjour à l'USI comme le résultat secondaire. En l'absence de biopsie pulmonaire ouverte, les critères cliniques majeurs et mineurs (conformes à l'énoncé de l'American Thoracic Society) ont été utilisés pour diagnostiquer la FPI. Les infections étaient écartées grâce à des cultures de surveillance généralisées, à une bronchoscopie avec lavage bronchoalvéolaire ou aux deux.

RÉSULTATS : Quatre-vingt-huit dossiers ont été révisés, et 25 patients ont respecté les critères d'inclusion. L'âge moyen ( \pm ÉT) était de $69 \pm 11$ ans (fourchette entre 42 et 96 ans), et 23 patients étaient de sexe masculin. À l'exception d'un patient qui a obtenu son congé à domicile, 21 patients sont décédés pendant qu'ils recevaient une ventilation mécanique, et trois patients sont morts à l'hôpital peu après le congé de l'USI (un jour, 22 jours et 67 jours). Une intubation et une ventilation mécanique ont été administrées à 21 patients, pendant une durée moyenne de $11 \pm 6$ jours (fourchette de deux à 27 jours), tandis que les quatre autres patients ont été traités par ventilation non effractive. La durée moyenne des symptômes avant l'admission à l'USI était de $22 \pm 26$ jours. Tous les patients ont reçu des corticoïdes systémiques, et huit patients ont reçu une chimiothérapie supplémentaire.

CONCLUSION : En l'absence de cause réversible, il se peut que les patients atteints de FPI qui développent une exacerbation aiguë de leur maladie ne bénéficient pas d'une admission à l'USI et d'une ventilation mécanique. Cependant, il est impératif de procéder à un bilan diagnostique pour écarter une cause infectieuse ou une autre cause réversible d'insuffisance respiratoire avant de refuser l'hospitalisation à l'USI. diopathic pulmonary fibrosis (IPF) is a progressive and ulti-
mately fatal interstitial lung disease of unknown etiology
$(1,2)$. Median survival of patients with IPF has been reported
to range from three to five years $(3,4)$. The current treat-
ments for IPF include corticosteroids and cytotoxic agents;
these improve neither the survival nor the quality of life
(5,6). Although there is recent evidence to support the ben-
efit of newer antifibrotic agents such as interferon gamma, the data are still preliminary (7-9). In the majority of patients, the natural course of the disease is chronic and progressive, although abrupt worsening occurs in some patients $(1,10)$. The causes of such exacerbations remain uncertain, and appropriate therapy for this condition has not been established (11-13).

For many years, intensive care unit (ICU) admission and initiation of mechanical ventilation (MV) has been consid-

Sections of Respirology and Critical Care Medicine, Department of Internal Medicine, University of Manitoba, Winnipeg, Manitoba

Correspondence and reprints: Dr Sat Sharma, Associate Professor, University of Manitoba, Site Coordinator, Department of Respirology,

St Boniface General Hospital, BG034, 409 Tache Avenue, Winnipeg, Manitoba R2H 2A6. Telephone 204-237-2217, fax 204-231-1927,

e-mail Ssharma@sbgh.mb.ca 
ered to be the standard treatment for patients with IPF who develop acute exacerbation and hypoxemic respiratory failure of unknown etiology $(14,15)$. However, the benefit from invasive supportive therapy is unclear $(16,17)$.

The aim of the present study was to evaluate the outcome and the beneficial effect of ICU admission in patients with IPF who require ICU admission for acute respiratory failure (ARF) of unknown etiology.

\section{Selection of patients}

\section{METHODS}

A computerized register of patients admitted to the ICU at University of Manitoba hospitals was used. All patients with IPF requiring MV for unknown causes of ARF who were admitted to the medical and surgical ICU units (each unit has 10-bed capacity) at the Health Sciences Centre of the University of Manitoba, Winnipeg, Manitoba, from November 1988 to December 2000 were retrospectively studied. All patients admitted to the medical and surgical ICU units at the St Boniface General Hospital, Winnipeg, Manitoba, from June 1999 to December 2000 for similar indications were also reviewed. A total of 25,447 records were searched during the combined period. The following diagnoses were searched for: ICU admission primarily due to IPF exacerbation (71 records), and underlying IPF patients admitted to the ICU for reasons other than IPF exacerbation (32 records). After excluding repeated names and one inter-ICU transfer, the search was narrowed to 88 charts. IPF was defined as a specific form of chronic fibrosing interstitial pneumonia of unknown etiology with the histological appearance of usual interstitial pneumonia (UIP) on surgical (thoroscopic or open) lung biopsy. Inclusion criteria were: age 18 years and older, an established diagnosis of IPF and acute exacerbation of IPF that required ICU admission.

In the absence of surgical lung biopsy, IPF was diagnosed based on the presence of all of the major diagnostic criteria, as well as at least three of the four minor criteria. The major criteria included: exclusion of other known causes of interstitial lung disease such as certain drug toxicities, environmental exposures and connective tissue diseases; abnormal pulmonary function studies that included evidence of restriction (reduced vital capacity, often with an increased forced expiratory volume in 1 s/forced vital capacity ratio) and impaired gas exchange (increased alveolar to arterial oxygen gradient of the partial pressure of oxygen $\left[\mathrm{PaO}_{2}\right]$ at rest or exercise or decreased diffusion capacity of the lung for carbon monoxide); bibasilar reticular abnormalities with minimal ground glass opacities on high resolution computed tomography (HRCT) scan; and transbronchial lung biopsy or bronchoalveolar lavage (BAL) showing no features supporting an alternative diagnosis. The minor criteria included: age older than 50 years; insidious onset of otherwise unexplained dyspnea on exertion; duration of illness three months or longer; and bilateral inspiratory crackles.

Acute exacerbation of IPF was defined by the following criteria: exacerbation of dyspnea within eight to 12 weeks; development of adult respiratory distress syndrome (ARDS) criteria (based on the American and European consensus conference [13]); absence of apparent infectious agents; and ICU admission for further diagnostic workup and management. The exclusion criteria included: evidence of connective tissue disorders or hypersensitivity pneumonitis; presence of infection in the first five days of ICU admission; evidence of severe left ventricular dysfunction, documented as an ejection fraction of less than 30\%; significant history of occupational exposure; and patients with irreversible systemic disease, eg, end-stage neoplasm.

\section{Data collection}

The following data were collected from the medical charts: age, sex, duration of symptoms before ICU admission in days, bibasilar dry crackles on chest examination, chest radiograph findings, computed tomography (CT) chest findings, open lung biopsy results and the timing from the ICU admission to the lung biopsy, bronchoscopy findings, corticosteroid therapy, immunosuppressive therapy, antibiotic therapy, Acute Physiological and Chronic Health Evaluation II score, length of stay score, Therapeutic Intervention Scoring System (TISS) score, use of noninvasive and invasive $\mathrm{MV}, \mathrm{PaO}_{2}$ value measured during $\mathrm{MV}$, the $\mathrm{PaO}_{2} /$ fraction of inspired oxygen $\left(\mathrm{FIO}_{2}\right)$ ratio and positive end-expiratory pressure (PEEP) level. The APACHE is widely used for the assessment of illness severity; it predicts hospital mortality in ICUs, and combines a chronic health evaluation and acute physiology score. The TISS is a measure of workload and is valuable to evaluate resource use in ICUs. The most recent results of pulmonary function tests performed before the current hospitalization were also recorded.

Infections were ruled out by extensive surveillance cultures (including sputum, blood and urine cultures) and/or bronchoscopy with BAL in the first five days of ICU admission. The diagnosis of pneumonia was considered if the patient met the following criteria: fever and deterioration of pulmonary status with appearance of a new pulmonary infiltrate on chest radiograph, and documented pulmonary pathogens.

\section{Outcome measures}

The primary end point was survival at hospital discharge. The secondary end points were ICU length of stay and duration of MV, hospital stay after ICU discharge, and the benefit of corticosteroids and/or chemotherapy treatment.

\section{Statistical analysis}

All comparisons were unpaired. Continuous variables were expressed as mean \pm SD for normally distributed variables and were compared using Student's $t$ test.

A survival curve was estimated using the Kaplan-Meier method. Multiple comparisons between continuous variables were made using analysis of variance for repeated measures. $\mathrm{P} \leq 0.05$ was considered statistically significant.

\section{Patient characteristics}

\section{RESULTS}

Of the 88 patients admitted with a diagnosis of IPF, 25 patients met the inclusion criteria. The other 63 patients were excluded for the following reasons: infections $(n=11)$, coronary artery bypass grafting and/or valvular heart disease $(n=8)$, lung transplants $(n=6)$, coronary artery disease and heart failure $(n=4)$, connective tissue diseases $(n=6)$, surgery $(n=4)$, asbestosis $(n=1)$, silicosis $(n=1)$, drugs and chemotherapy $(n=2)$, ARDS and/or acute interstitial pneumonitis (AIP) in the absence of a previously documented IPF diagnosis $(n=2)$, Guillain-Barré syndrome and IPF $(n=2)$, disseminated tuberculosis $(n=1)$, lymphoma $(n=2)$ and upper 
TABLE 1

\begin{tabular}{|c|c|}
\hline Patient characteristics & All patients \\
\hline Mean age in years (mean $\pm S D$, range) & $69 \pm 11$ (42 to 96$)$ \\
\hline Male/female sex (n) & $23 / 2$ \\
\hline $\begin{array}{l}\text { Duration of symptoms before intensive care unit } \\
\text { admission in days (mean } \pm S D \text {, range) }\end{array}$ & $22 \pm 26$ (2 to 90$)$ \\
\hline Bibasilar dry crackles $(n)$ & $25 / 25$ \\
\hline Vital capacity $(\%$ predicted $)($ mean \pm SD) & $56 \pm 15$ \\
\hline $\begin{array}{l}\text { Diffusion capacity of the lung for } \\
\text { carbon monoxide ( } \% \text { predicted) (mean } \pm \text { SD) }\end{array}$ & $37 \pm 10$ \\
\hline Basal and peripheral pulmonary fibrosis on CXR (n) & $25 / 25$ \\
\hline Honeycombing on computed tomography of the chest (n) & $12 / 12$ \\
\hline Lung biopsy (n) & $5 / 25$ \\
\hline $\begin{array}{l}\text { Time from intensive care unit admission to lung biopsy } \\
\text { in days (mean } \pm \text { SD) }\end{array}$ & $4 \pm 4$ \\
\hline Corticosteroid therapy $(n)$ & $25 / 25$ \\
\hline Immunosuppressive therapy (n) & $8 / 25$ \\
\hline Antibiotics (n) & $25 / 25$ \\
\hline Bronchoscopy (n) & $14 / 25$ \\
\hline
\end{tabular}

CXR Chest $x$-ray

gastrointestinal bleeding $(n=1)$; and 12 patients did not meet IPF criteria.

The baseline characteristics of the 25 patients are laid out in Table 1 . Their mean age was 69 years; 23 were male and two were female. The average duration of symptoms before ICU admission was 22 days, and all had bibasilar inspiratory crackles on auscultation. Results of pulmonary function tests performed in the year before ICU admission were available for 12 patients; these demonstrated a restrictive ventilatory impairment compared with predicted values. The mean forced vital capacity was $56 \%$ predicted and the carbon monoxide diffusing capacity was $37 \%$ predicted of alveolar volume. The radiological findings of basal and peripheral pulmonary fibrosis were present in all 25 patients on chest radiograph, and honeycombing was found on all 12 of the high resolution scans that were available for review. Lung biopsy was performed in a minority of the patients (five of 25). All patients received treatment with corticosteroids, and despite the absence of a documented infection, all received antibiotics as well. A smaller number $(31 \%)$ were treated with immunosuppressive agents, predominantly cyclophosphamide.

In eight of the 25 patients (32\%), the diagnosis of IPF was confirmed through histological examination by open lung biopsy specimen before ICU admission $(n=5)$ or by autopsy $(n=3)$. In all eight patients, the lung biopsy specimens showed histological features of UIP, with areas of extensive fibrosis and honeycomb changes. The extent of the disease was heterogeneous. In the other 17 patients, clinical, functional and radiological features were used to make the diagnosis of IPF.

Clinical status of patients at ICU admission

At the time of ICU admission and after initiation of $\mathrm{MV}$, all patients had severe hypoxemia with a $\mathrm{PaO}_{2} / \mathrm{FIO}_{2}$ ratio of $113 \pm 40 \mathrm{mmHg}$ despite high oxygen flow; the average $\mathrm{FIO}_{2}$ was
TABLE 2

\begin{tabular}{lc} 
Clinical status of patients at intensive care unit admission \\
for acute exacerbation of idiopathic pulmonary fibrosis \\
\hline Variables (mean \pm SD) & Data \\
\hline Fraction of inspired oxygen (units) & $0.75 \pm 0.17$ \\
Partial pressure of arterial oxygen/Fraction of inspired oxygen & $113 \pm 40$ \\
Positive end-expiratory pressure $\left(\mathrm{cm} \mathrm{H}_{2} \mathrm{O}\right)$ & $7 \pm 2$ \\
Acute Physiological and Chronic Health Evaluation II score & $19.72 \pm 1$ \\
Therapeutic Intervention Scoring System score & $31.33 \pm 2$ \\
\hline
\end{tabular}

TABLE 3

Outcome measures of patients admitted to the intensive care unit for acute exacerbation of idiopathic pulmonary fibrosis

\begin{tabular}{lc}
\hline Variables & Data \\
\hline Intensive care unit length of stay in days (mean \pm SD, range) & $11 \pm 6(2$ to 27$)$ \\
Invasive mechanical ventilation $(n)$ & $21 / 25$ \\
Noninvasive mechanical ventilation $(n)$ & $3 / 25$ \\
Survival ratio $(n)$ & $1 / 25$ \\
Mortality ratio $(n)$ & $24 / 25$ \\
\hline
\end{tabular}

$0.75 \% \pm 0.17 \%$. Twenty-four patients received PEEP at an average level of $7 \pm 2 \mathrm{~cm} \mathrm{H}_{2} \mathrm{O}$, while seven of them received PEEP at $10 \mathrm{~cm} \mathrm{H}_{2} \mathrm{O}$ or more. One patient did not receive PEEP. Their average Acute Physiological and Chronic Health Evaluation II score was $19.72 \pm 1$. The mean TISS score was $31.33 \pm 2$ (Table 2).

The average time from ICU admission to open lung biopsy was $4 \pm 4$ days. The open lung biopsies were performed from moderately affected areas as per the HRCT scans. All cases demonstrated diffuse thickening of the alveolar walls with inflammatory cell infiltration and the presence of fibroblastic foci. Hyaline membranes were absent, and regeneration of alveolar epithelium was evident. These changes are the hallmark of organizing diffuse alveolar damage (DAD). The changes were superimposed on a background of peripheral temporally heterogeneous fibrosis and distortion of lung architecture, which is diagnostic of chronic interstitial pneumonitis of the UIP type. Results of staining for organisms was negative.

Intubation and MV was administered to 21 patients for a mean duration of 11 days (range two to 27 days). The other four patients were treated with noninvasive ventilation (three patients) - two with bilevel positive airway pressure, one with proportional assist ventilation and one with high flow oxygen alone. The latter individual was included in the present study because he would have been treated with MV, but he chose not to pursue this treatment (Table 3). All patients were treated with antibiotics and systemic corticosteroids, while eight patients received chemotherapy additionally.

\section{Outcome measures}

Twenty-one patients died in the ICU while receiving MV, and three patients died in hospital shortly (one day, 22 days and 67 days) after ICU discharge. The overall mortality was more than $96 \%$, and only one patient survived to be 


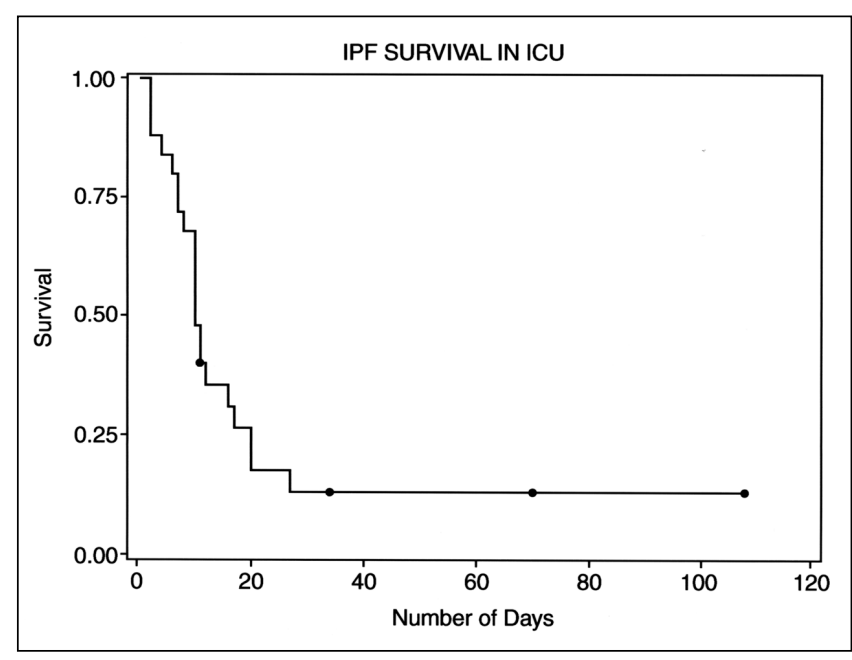

Figure 1) A Kaplan-Meier survival curve for patients with idiopathic pulmonary fibrosis (IPF) admitted to the intensive care unit (ICU) with unknown cause of respiratory failure

discharged home (Table 3, Figure 1). Hypoxemia and hospital-acquired pneumonia were the causes of death in most of the patients. The only survivor discharged from hospital spent 31 days on the medical ward before being sent home; he was readmitted to the hospital medical ward 30 days later and died in hospital. This patient was a 69-year-old man who presented with a two-week history of shortness of breath and dry cough; his chest radiograph showed bilateral basal alveolar-interstitial densities, and HRCT revealed bilateral basal fibrosis with traction bronchiactasis and minimal ground glass opacity. His oxygen $\mathrm{PaO}_{2} / \mathrm{FIO}_{2}$ ratio was $66 \%$ on PEEP of $10 \mathrm{~cm} \mathrm{H} \mathrm{H}_{2} \mathrm{O}$. He was treated with high dose corticosteroids, and he stayed for 17 days in the ICU and for 18 days on the medical ward before discharge. This patient died of hypoxemia on readmission.

\section{DISCUSSION}

IPF is a progressive and ultimately fatal interstitial lung disease of unknown etiology $(1,2)$. Natural progression of IPF causes gradual clinical deterioration and death, which naturally occurs over three to five years. In a meta-analysis of 543 patients reported by Panos and colleagues (1), respiratory failure secondary to IPF progression and pulmonary infection caused death in $38 \%$ and $2.8 \%$ of patients, respectively. In some cases of IPF, a more accelerated course ensues.

We investigated the issue of whether ICU admission and invasive and/or noninvasive MV affects the outcome of ARF caused by acute exacerbation of IPF. We reviewed all of the charts of patients with IPF admitted to the ICU over a period of 12 years. Of the 88 patients identified, causes of admission were heterogenous. Based on strict criteria, we included only those who had no identifiable causes. Infections were ruled out by extensive surveillance culture and/or bronchoscopy with BAL in the first five days in the ICU. Twenty-five patients met the inclusion criteria. The diagnosis of IPF was confirmed by histological examination in eight of the 25 patients (32\%) (by open lung biopsy specimen before admission to the ICU $[n=5]$ and by autopsy [n=3]). Major and minor criteria based on American Thoracic Society recommendations led to the diagnosis in the rest of the patients (6). Twenty-four patients died during this admission - a mortality rate of $96 \%$ (21 patients died in the ICU while receiving MV, and three patients died in hospital shortly after ICU discharge). The only patient who survived to discharge spent 31 days in total in the hospital before he was sent home; he was readmitted to the hospital medical ward after one month and died in hospital.

In recent series $(16,17)$, outcomes of patients with IPF referred to the ICU for ARF were very poor and were not improved by supportive MV. However, these two series included all of the cases of IPF that required ICU admission; the authors did not discriminate between patients with and without an identifiable reversible cause for acute exacerbation. Some of these patients were also listed for lung transplantation (17). Among the four (of 15) patients discharged from the ICU, the precipitating cause of ARF was readily reversible in three patients (pneumothorax in two patients and general anesthesia in one patient) (16). The authors concluded that without a clearly identified, reversible cause of ARF, these patients would not have benefited from admission to the ICU. Influenza-like syndromes may have been the precipitating cause in some of these patients as per Kondoh et al (14); however, no evidence of influenza infection was found in our series.

Most patients with IPF typically develop a slowly progressive, deteriorating course, resulting in respiratory failure and death over a median duration of three to six years (2-4). However, rapid progression of interstitial pneumonitis, resulting in respiratory failure over a few months, may occur in patients with a previously established diagnosis of IPF. AIP or Hamman-Rich syndrome occurs in previously healthy individuals and is diagnosed by lung biopsy findings showing organizing DAD (18). A similar disorder in patients with IPF - 'acute exacerbation of IPF' - presents with symptoms of progressive dyspnea and often leads to respiratory failure (19). The radiological findings demonstrate multifocal or diffuse opacities, ground glass attenuation and consolidation on HRCT. Additionally, subpleural honeycombing and traction bronchiectasis may also be seen in the background. Eventually, distortion of lung architecture, traction bronchiectasis and cystic lesions develop (20). Recently, Rice et al (21) reported that on gross pathology in patients with acute exacerbation of IPF, the lungs are heavy and nodular, and show shrinkage of the lower lobes (ie, the findings of UIP). Also evident were superimposed hemorrhage and consolidation, suggestive of DAD. On histological examination, the buds of intra-alveolar organization of DAD are found away from the areas of fibroblastic foci that reflect UIP.

In the literature, the terminology referring to acute exacerbation of IPF is confusing. In 1997 and 1999, Akira (22) and colleagues (23) described radiological and pathological findings of fulminant forms of IPF, and characterized CT scan findings into two different processes: "accelerated variant of usual interstitial pneumonitis" and "acute exacerbation of idiopathic pulmonary fibrosis". The patients were classified according to the CT scan features of peripheral parenchymal 
opacification, multifocal parenchymal opacification or diffuse parenchymal opacification. Biopsy or autopsy findings showed acute fibroblastic foci in patients with peripheral opacities (ie, findings of UIP), whereas DAD and UIP findings were evident in patients with multifocal and diffuse opacities. Both the peripheral and parenchymal (multifocal or diffuse) opacities were thought to represent the accelerated phase of IPF (22). However, a later study by Akira (22) did not support this classification system. The present authors find this classification to be confusing and believe that 'accelerated phase of IPF' and 'acute exacerbation of IPF' denote the indistinguishable clinical, radiological and pathological processes of AIP superimposed on UIP. Rice et al (21) recently described this syndrome as "terminal diffuse alveolar damage in patients with IPF". The present authors prefer the term 'acute exacerbation of IPF' to describe the development of DAD in patients with underlying, chronic, progressive IPF. All of the patients in our series demonstrated clinical, pathological and radiological features consistent with this entity (Figure 2). Whether UIP transforms into AIP (ie, acute exacerbation of IPF) as a terminal event or secondary to an unknown exogenous cause of DAD, is not known.

All patients in our series were treated with high dose corticosteroid therapy. Additionally, immunosuppressive therapy with cyclophosphamide was prescribed to eight of 25 patients (31\%). No beneficial responses were observed. This is in contrast to the three cases described by Kondoh et al (14), who were successfully treated with $1000 \mathrm{mg} /$ day of methylprednisolone. Akira (22) effectively treated nine of 17 patients with $1000 \mathrm{mg} /$ day of methylprednisolone. In his study, the mortality rates were $17 \%$ in patients with peripheral opacities, $50 \%$ in patients with multifocal opacities and $100 \%$ in patients with diffuse opacities (23). Late-phase ARDS and AIP also exhibit organizing DAD on lung biopsy, similar to the histological findings in acute exacerbation of IPF. However, despite histological similarities, the two diseases behave differently with respect to the prognosis and response to corticosteroids (22-25). Given the poor prognosis of acute exacerbation of IPF, a trial of high dose corticosteroids may be appropriate, although a uniformly poor response to therapy was noted in our series.

\section{REFERENCES}

1. Panos RJ, Mortenson RL, Nicolli SA, et al. Clinical deterioration in patients with idiopathic pulmonary fibrosis: Cause and assessment. Am J Med 1990;88:396-404.

2. Wells AU, du Bois RM. Prediction of disease progression in idiopathic pulmonary fibrosis. Eur Respir 1994;7:637-9.

3. Turner-Warwick M, Burrows B, Johnson A. Cryptogenic fibrosing alveolitis: Clinical features and their influence on survival. Thorax 1980;35:171-80.

4. Hubbard R, Johnston I, Britton J. Survival in patients with cryptogenic fibrosing alveolitis: A population-based cohort study. Chest 1998;113:396-400.

5. Raghu G, Depaso WJ, Cain K, et al. Azathioprine combined with prednisone in the treatment of idiopathic pulmonary fibrosis: A prospective double-blinded, randomized, placebo-controlled clinical trial. Am Rev Respir Dis 1991;144:291-6.

6. Johnson MA, Kwan S, Snell NJ, et al. Randomised controlled trial comparing prednisolone alone with cyclophosphamide and low dose prednisolone in combination in cryptogenic fibrosing alveolitis. Thorax 1989;44:280-8.

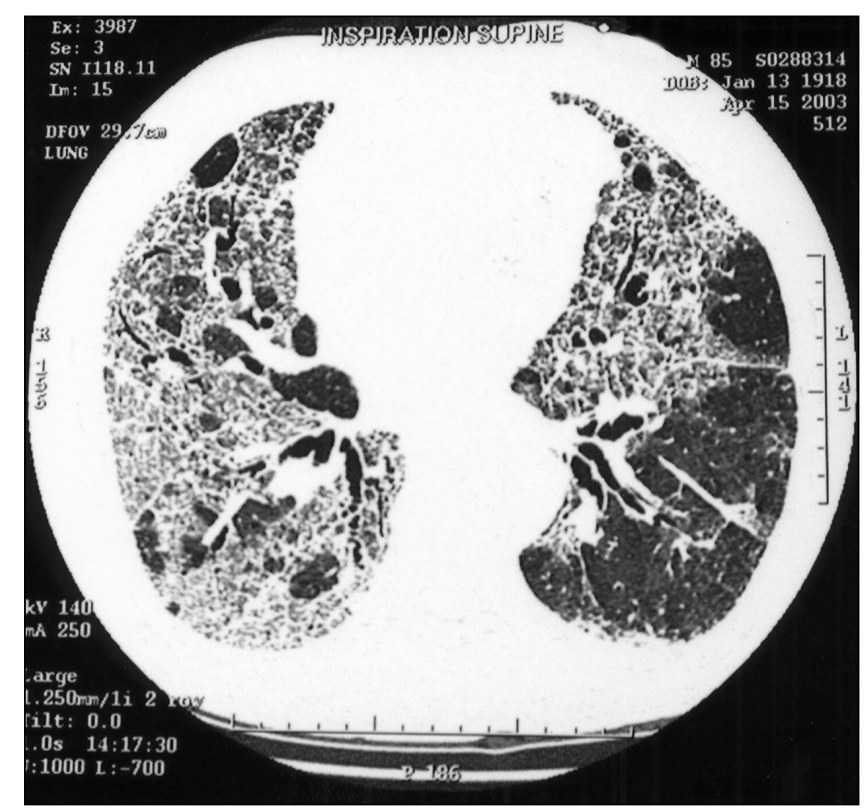

Figure 2) High resolution computed tomography scan showing multifocal parenchymal opacities, ground glass opacification and peripheral honeycombing. These are characteristic radiological features of acute exacerbation of idiopathic pulmonary fibrosis

\section{CONCLUSIONS}

IPF, also known as cryptogenic fibrosing alveolitis, is a fatal disorder, with the median survival reported as being between three and six years. Although chronic progression over time is characteristic of IPF, some patients develop abrupt deterioration. The radiological and pathological findings in these patients demonstrate development of an additional disorder, eg, organizing acute lung injury pattern (DAD) superimposed on the background findings of UIP. The patients with established IPF who develop ARF may require ICU admission for workup to elucidate a cause for deterioration. Our study suggests that once a reversible cause is excluded, these patients have an extremely poor prognosis. There is a paucity of published literature in this area, and additional studies are needed to improve our understanding of 'acute exacerbation of IPF'.

7. Selman M, Carrillo G, Salas J, et al. Colchicine, D-penicillamine and prednisone in the treatment of idiopathic pulmonary fibrosis: A controlled clinical trial. Chest 1998;114:507-12.

8. Raghu G, Johnson WC, Lockhart D, et al. Treatment of idiopathic pulmonary fibrosis with a new antifibrotic agent, pirfenidone: Results of a prospective, open-label phase II study. Am J Respir Crit Care Med 1999;159:1061-9.

9. Ziesche R, Hofbauer E, Wittmann K, et al. A preliminary study of longterm treatment with interferon- $1 \beta$ and low dose prednisolone in patients with idiopathic pulmonary fibrosis. N Engl J Med 1999;341:1264-9.

10. Ryu JH, Colby TV, Hartman TE. Idiopathic pulmonary fibrosis: Current concepts. Mayo Clin Proc 1998;73:1085-101.

11. Katzenstein AL, Myers JL. Idiopathic pulmonary fibrosis. Am J Respir Crit Care Med 1998;157:1301-15.

12. Gay SE, Kazerooni EA, Toews GB, et al. Idiopathic pulmonary fibrosis: Predicting response to therapy and survival. Am J Respir Crit Care Med 1998;157:1063-72.

13. Idiopathic pulmonary fibrosis: Diagnosis and treatment. International consensus statement. American Thoracic Society (ATS), and the 
European Respiratory Society (ERS). Am J Respir Crit Care Med 2000;161:646-64.

14. Kondoh Y, Taniguchi H, Kawabata Y, et al. Acute exacerbation in idiopathic pulmonary fibrosis: Analysis of clinical and pathologic findings in three cases. Chest 1993;103:1808-12.

15. Nava S, Rubini F. Lung and chest mechanics in ventilated patients with end stage idiopathic pulmonary fibrosis. Thorax 1999;54:390-5.

16. Blivet S, Philit F, Sab JM. Outcome of patients With idiopathic pulmonary fibrosis admitted to the ICU for respiratory failure. Chest 2001;120:209-12.

17. Stern J-B, Mal H, Groussard O. Prognosis of patients with advanced idiopathic pulmonary fibrosis requiring mechanical ventilation for acute respiratory failure. Chest 2001;120:213-9.

18. Vourlekis JS, Brown KK, Cool CD, et al. Acute interstitial pneumonitis. Case series and review of the literature. Medicine 2000;79:369-78.

19. Bouros D, Nicholson AC, Polychronopoulos V, du Bois RM. Acute interstitial pneumonia. Eur Respir J 2000;15:412-8.
20. Colby TV, Lombard C, Yousem SA, Kitaichi M. Atlas of Pulmonary Surgical Pathology. Philadelphia: Saunders, 1991:228-46.

21. Rice A, Wells AU, Bouros D, et al. Terminal diffuse alveolar damage in relation to interstitial pneumonias. Am J Clin Pathol 2003;119:790-14.

22. Akira M. Computed tomography and pathologic findings in fulminant forms of idiopathic interstitial pneumonia. J Thorac Imaging 1999;14:76-84.

23. Akira M, Hamada H, Sakatani M, Kobayashi C, Nishioka M, Yamamoto S. CT findings during phase of accelerated deterioration in patients with idiopathic pulmonary fibrosis. AJR Am J Roentgenol 1997;168:79-83.

24. Nishiyama O, Shimuzu M, Ito Y, et al. Effect of prolonged low-dose methylprednisolone therapy on acute exacerbation of idiopathic pulmonary fibrosis. Respir Care 2001;46:698-701.

25. Meduri GU, Headley AS, Golden E, et al. Effect of prolonged methylprednisolone therapy in unresolving acute respiratory distress syndrome: A randomized controlled trial. JAMA 1998;280:159-65. 


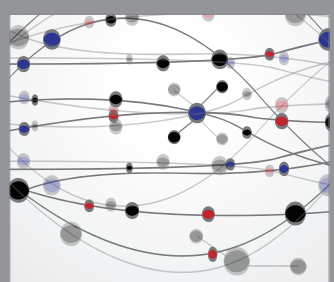

The Scientific World Journal
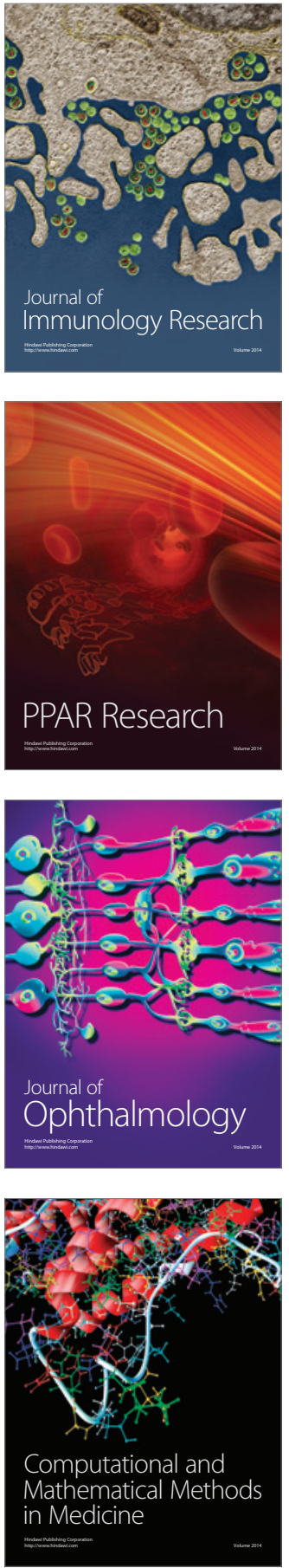

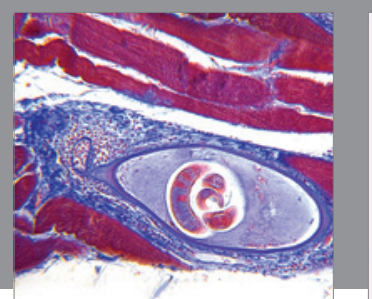

Gastroenterology Research and Practice

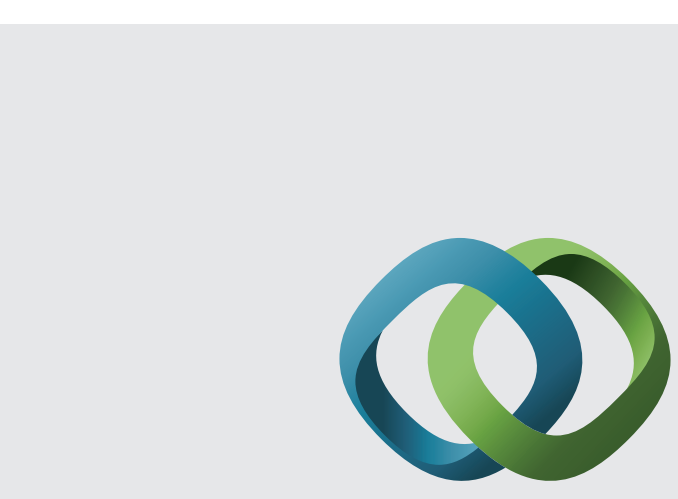

\section{Hindawi}

Submit your manuscripts at

http://www.hindawi.com
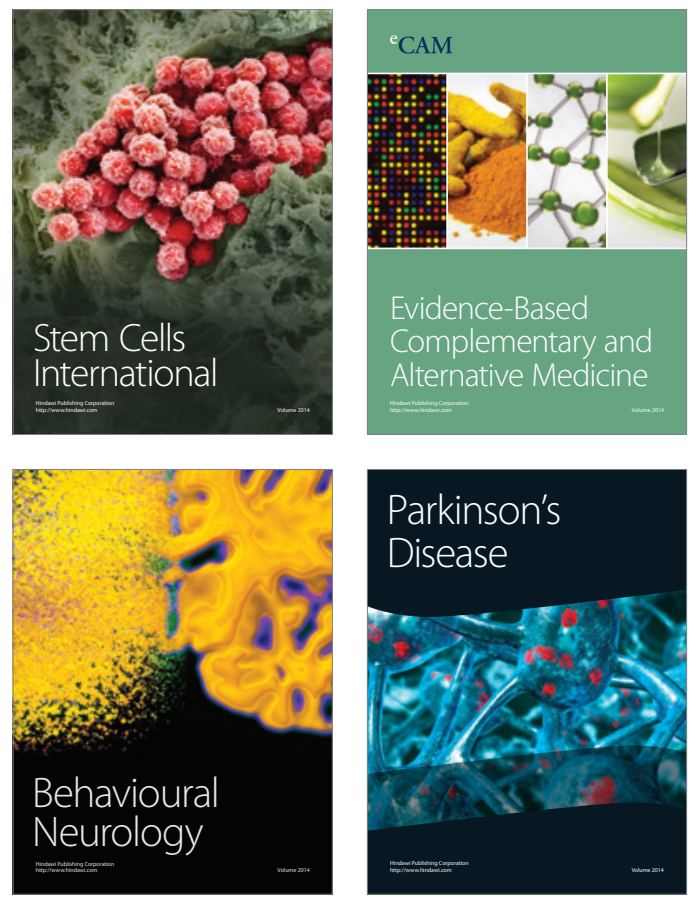
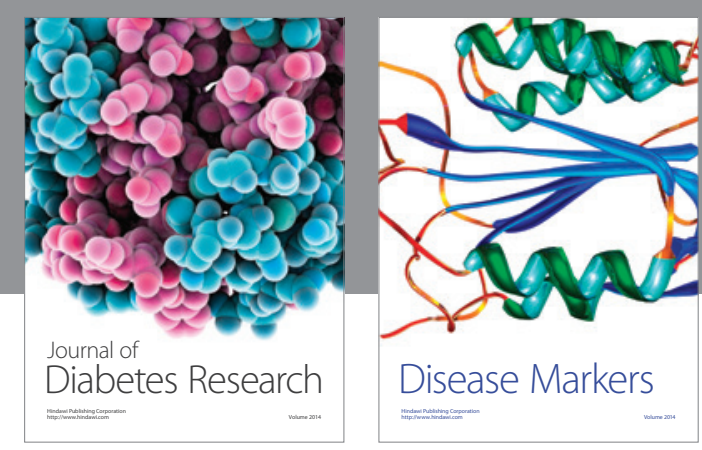

Disease Markers
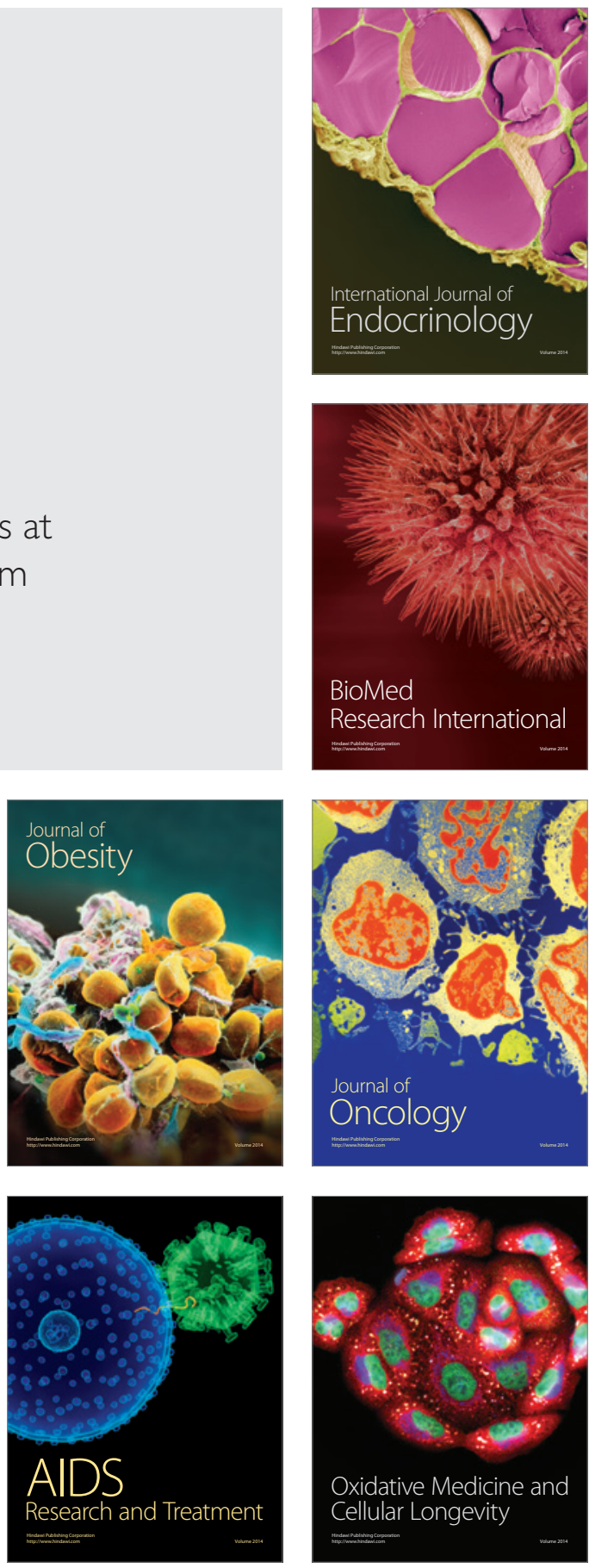